\title{
RELATO DE EXPERIÊNCIA: MUSICOGRAFIA BRAILLE NA UNIVERSIDADE DE BRASÍLIA
}

\section{EXPERIENCE REPORT: BRAILLE MUSIC AT THE UNIVERSITY OF BRASÍLIA}

\author{
Carolina Dias Pinheiro ${ }^{1}$ \\ Andréa Menêzes da Costa Gama² \\ Renato de Vasconcellos ${ }^{3}$ \\ Ana Karoline Versiane Soares Araújo ${ }^{4}$ \\ Esther de Almeida Costa ${ }^{5}$ \\ João Paulo dos Santos Oliveira ${ }^{6}$ \\ Lucas Souza Pinheiro ${ }^{7}$ \\ Mariana de Almeida Medina ${ }^{8}$ \\ Vandeval Lopes da Silva ${ }^{9}$ \\ Victor Hugo Queiroz Porto ${ }^{10}$ \\ Vitória Nara de Freitas Paulo ${ }^{11}$
}

RESUMO: Trata-se de relato de experiência do projeto "Adaptação de materiais acadêmicos para musicografia braille", durante o segundo semestre de 2019. O propósito do projeto foi transcrever as partituras e adaptar outros materiais musicais para estudantes de Música na Universidade de Brasília com deficiẽncia visual. Os transcritores eram alunos bolsistas, que analisavam cada material, definiam quais métodos deveriam ser empregados e então atribuíam funções entre si, de forma que alguns realizavam a transcrição para musicografia enquanto outros faziam a adaptação de imagens, descrições e revisão. Os resultados foram positivos. Os alunos relatam a satisfação em aprender uma nova habilidade profissional e em participar da promoção da acessibilidade. Notou-se a necessidade de maior estudo sobre o uso de softwares como ferramentas de transcrição. Há perspectiva de projetos futuros de pesquisa e extensão na área. Conclui-se que mais alunos de música precisam ser apresentados à musicografia braille em sua formação, de forma multidisciplinar.

Palavras-chave: Musicografia braille. Acessibilidade. Deficiência visual. Universidade de Brasília.

\footnotetext{
${ }^{1}$ Revisora de Textos Braille na Universidade de Brasília. E-mail: carolinadias94@gmail.com

2 Professora no CEP Escola de Música de Brasília. E-mail: andrea.musicasmed@gmail.com

${ }^{3}$ Professor de piano popular na Universidade de Brasília. E-mail: renato.vasconcellos@gmail.com

${ }^{4}$ Graduanda em Licenciatura em Língua de Sinais Brasileira - Português como segunda língua (LSB - PSL). Email: karolversiane@gmail.com

${ }^{5}$ Assistente em Administração na Universidade de Brasília. E-mail: estheralmeida15@gmail.com

${ }^{6}$ Graduando em Música/Licenciatura pela UnB. E-mail: jp110591@gmail.com

${ }^{7}$ Licenciado em música na UnB (instrumento Viola). Cursando Bacharelado. E-mail: lucass.pinheiro@hotmail.com

${ }^{8}$ Bacharela em Línguas Estrangeiras Aplicadas e cursando Língua Francesa e Respectiva Literatura. E-mail: marianadea.medina@gmail.com

${ }^{9}$ Graduado em Letras/Japonês pela UnB. Cursando Letras/Espanhol. E-mail: vander_val@hotmail.com

${ }^{10}$ Graduando em Música/licenciatura pela UnB. E-mail: victor.hqp2@gmail.com

${ }^{11}$ Graduanda em Filosofia/licenciatura pela UnB. E-mail: leishes@gmail.com
} 
ABSTRACT: This is an experience report of the project "Adaptation of academic materials for braille music", during the second semester of 2019. The purpose of the project was to transcribe music scores and adapt other materials for visually impaired music students enrolled at the University of Brasilia. The transcribers were students (scholarship-holders), who analyzed each material, defined which methods should be used, and then assigned functions to each other, as some performed the transcription for braille music while others did the adaptation of images, descriptions, and proofreading. The result was generally positive. Satisfaction in learning a new professional skill and in participating in accessibility actions was reported by the students. Needs for further study on the use of software as transcription tools were noted. There is a prospect of future research and extension projects in the area. In conclusion, more music students need to be introduced to Braille music during their education, in a multidisciplinary way.

Key-words: braille music code; accessibility; visual impairment; University of Brasilia

\section{INTRODUÇÃO}

O acesso ao material transcrito para o Braille é de grande importância para a pessoa com deficiência visual e equipara-se ao material impresso em tinta para a pessoa vidente. Sem acesso aos textos, gráficos e, no caso específico do estudante de música, às partituras, não é possível prosseguir no curso com bom aproveitamento.

Em busca de soluções para o atendimento aos estudantes com deficiência visual usuários do sistema braille matriculados no curso de Licenciatura em Música da Universidade de Brasília, foi criado o projeto "Adaptação de Materiais Acadêmicos para a Musicografia Braille" com o objetivo de transcrever partituras e adaptar outros materiais das disciplinas específicas de música. O projeto teve o envolvimento de representantes do corpo docente, discente (bolsistas) e técnico-administrativo da Universidade e foi executado pela Diretoria de Acessibilidade ${ }^{12}$ do Decanato de Assuntos Comunitários (DACES/DAC) da Universidade.

O presente trabalho é um relato da experiência desenvolvida através do projeto, no período de agosto a dezembro de 2019 (segundo semestre letivo) na Universidade de Brasília. Nesse período, a principal usuária dos materiais transcritos foi uma aluna com cegueira total, regular do curso de licenciatura em música. A iniciativa da universidade partiu da indispensabilidade dos materiais adaptados para permanência e aproveitamento do curso pela aluna atendida. Ademais, durante a experiência do projeto percebeu-se a carência de fontes de informação sobre situações similares (outros relatos de experiência, publicações e pesquisas na área de musicografia em contexto universitário), fato que foi o principal motivador para a escrita

\footnotetext{
12 Quando o projeto teve início, a DACES era então a Coordenação do Apoio à Pessoa com Deficiência (PPNE).
} 
conjunta do presente texto. O principal objetivo dos autores com a divulgação desta experiência é contribuir com a divulgação de ações práticas na área de musicografia braille nas universidades brasileiras, além de abrir uma porta de diálogo com outras instituições, profissionais, pesquisadores e estudantes.

O período selecionado para este relato compreende os meses de agosto a dezembro de 2019 (segundo semestre no calendário acadêmico da UnB). Esse foi o primeiro semestre em que o projeto de adaptação para musicografia braille esteve em atividade ${ }^{13}$. As transcrições foram realizadas por um grupo de alunos bolsistas, que após serem selecionados receberam treinamento em musicografia braille e realizaram os trabalho através da divisão de tarefas, discutindo quais os melhores métodos para adaptar um material e se dividindo a demanda em tarefas menores, com o apoio de ferramentas digitais (softwares próprios para transcrição braille).

A estrutura do relato seguirá a seguinte ordem: introdução à musicografia braille como sistema de escrita, apresentação das origens do projeto, seguida pela descrição das atividades e experiências relatadas e, por fim, considerações finais com resultados e perspectivas futuras.

\title{
MUSICOGRAFIA BRAILLE: DE UM CÓDIGO A OUTRO
}

Criado por Louis Braille no século 19, o código braille funciona através da representação em relevo de letras, símbolos e outros sinais, utilizando como base uma célula de seis pontos, cujas diferentes combinações formam variados referentes.

O código braille musical, ou Musicografia Braille, é a codificação específica desenvolvida por Louis Braille (que também era músico) para representar os sinais típicos da partitura musical. A musicografia braille como método de representação musical diferencia-se em diversos aspectos da escrita visual em tinta. Segundo Tomé (2007),

\begin{abstract}
A primeira e fundamental diferença origina-se do fato de escrever-se a música em linhas horizontais, tanto que a escrita visual utiliza o pentagrama, que permite o alinhamento vertical das notas que soam simultaneamente, inclusive quando a duração é diferente para cada uma delas. Supõe um obstáculo, especialmente para a escrita dos instrumentos polifônicos (piano, órgão,violão), que seguiria existindo ainda sem as graves limitações que impõe o braille. Isso converteu a transcrição da música para esses instrumentos, especialmente as obras de polifonia mais complexas, em uma verdadeira "tradução" a um sistema de escrita conceitualmente diferente e inadequado para expressar a música, o que torna imprescindível que essas transcrições sejam realizadas por pessoas que possuam, além do conhecimento profundo do braille, uma boa formação musical.
\end{abstract}

(TOMÉ, 2007, p. 05)

\footnotetext{
${ }^{13} \mathrm{O}$ projeto foi renovado para os semestres seguintes, e até o fechamento deste artigo mantinha-se em atividade.
} 
No Brasil, a Musicografia Braille em Língua Portuguesa está contemplada no Manual Internacional de Musicografia Braille, publicado em 2004 pelo Ministério da Educação ${ }^{14}$. Para muitos músicos e estudantes de música com deficiência visual, a musicografia braille permanece a forma principal para estudo de partituras.

\section{ORIGEM DO PROJETO}

A Universidade de Brasília (UnB) atua desde 1999 na promoção da acessibilidade para estudantes com deficiência e necessidades educacionais específicas na forma do Programa de Apoio às Pessoas com Necessidades Especiais (PPNE). Em 2017, o PPNE tornou-se a Coordenação de Apoio às Pessoas com Deficiência, e em 2020 passa a Diretoria de Acessibilidade, vinculada ao Decanato de Assuntos Comunitários (DACES/DAC).

As atividades desenvolvidas através da DACES envolvem ações e projetos que visam garantir condições para o desenvolvimento acadêmico dos estudantes, a partir da eliminação de barreiras e articulação entre unidades acadêmicas e administrativas da Universidade. A “Adaptação de materiais acadêmicos para musicografia braille” é um dos projetos nascidos dessas ações. O projeto começou em 2019 com o objetivo de oferecer material acadêmico adaptado aos estudantes com deficiência visual regularmente matriculados no curso de graduação em Música. Considerou-se ainda a legislação vigente que dispõe sobre a oferta de materiais adaptados para estudantes com deficiência, especialmente a Resolução CEPE n 048/2003 que trata dos direitos acadêmicos de estudantes com necessidades especiais na UnB e prevê "adaptação de recursos instrucionais: material pedagógico e equipamentos" (p. 02) e a Resolução CAD no 50/2019 que institui a Política de Acessibilidade da UnB, e também estabelece que a pessoa com deficiência poderá solicitar, entre outros: "a disponibilização de materiais didáticos e pedagógicos acessíveis, equipamentos de tecnologia assistiva destinados à visualização de textos, adaptação em Braille e/ou tamanho ampliado (...)" (p. 04).

\section{DESCRIÇÃO DO PROJETO E EXPERIÊNCIAS}

O projeto foi planejado através do intercâmbio de conhecimentos entre a DACES, o Departamento de Música da UnB e a Escola de Música de Brasília (EMB), em uma estrutura composta por alunos bolsistas da Universidade, tendo como exigência a capacidade de ler

\footnotetext{
${ }^{14}$ À época, o material foi publicado através da extinta Secretaria de Educação Especial (MEC/SEESP).
} 
partituras. Os candidatos foram avaliados e selecionados a partir da apresentação de cartas de intenções e de curriculum vitae. O treinamento em Musicografia Braille foi fornecido por professores da EMB atuantes no ensino de música para os alunos com deficiência visual daquela instituição.

Foram selecionados 4 bolsistas para atuar como transcritores, além de uma participante voluntária. Destes, três estudantes eram regulares do curso de Música e dois cursavam Letras, mas tinham formação musical prévia. A equipe contou ainda com a participação de mais uma bolsista para atuar apenas como apoio técnico à equipe nas descrições de imagens, revisão e preparo para impressão. O recurso orçamentário para concessão de bolsas era oriundo do Programa Incluir, e os alunos recebiam mensalmente. $\mathrm{O}$ trabalho foi coordenado pela Revisora Braille da UnB.

A equipe produziu, ao longo do referido semestre, uma apostila de coral com dez partituras de canto; cinco cânones para a disciplina Linguagem e Estruturação Musical; um livro completo de método de flauta doce soprano; três partituras de piano; e materiais e gráficos de matrizes para estudo de regência. Os materiais eram entregues à equipe diretamente pela aluna atendida, e quando necessário os professores das disciplinas eram procurados para esclarecer dúvidas sobre os materiais e sanar dúvidas.

A transcrição para Musicografia Braille foi feita através dos programas Braille Fácil (editor geral de textos braille), e MusiBraille (editor específico para partituras em braille). O processo em muitos casos foi além do uso da Musicografia Braille: considerando a natureza de alguns materiais, que envolviam além de texto musical, imagens e gráficos, os alunos combinaram conhecimentos, criatividade e trabalho em equipe para adaptar os conteúdos também com descrições, imagens táteis e gráficos em relevo usando o programa Monet (editor de imagens táteis). Nesses casos, o método de trabalho era uma ação de forma conjunta, na qual os alunos discutiam a natureza do material, definiam quais ferramentas deveriam ser empregadas e então atribuíam a cada membro uma função, de forma que alguns realizavam a transcrição para musicografia enquanto outros faziam a adaptação das imagens, descrições e revisão. Quando possível, o material era avaliado pela própria aluna antes de ser finalizado, e se necessário eram adicionadas notas de transcrição para maior clareza.

Sobre os principais desafios, os alunos relatam a insegurança por estarem se aventurando em um novo código e a memorização intensa das combinações --- o que no começo afetou a velocidade de produção das partituras, até que maior familiaridade e destreza fossem adquiridos. Relatam ainda a falta de publicações expondo as experiências de outros adaptadores, em especial 
para situações envolvendo materiais específicos e complexos em que os manuais não foram suficientes como guia (caso das partituras polifônicas, com muitos instrumentos e vozes no mesmo compasso, ou materiais com muitos gráficos, tabelas e imagens). Como ponto importante para superar esses desafios, os alunos citam o contato com os professores das disciplinas e com a aluna que recebia as adaptações. Para o apoio de impressão e revisão, os desafios estavam na diagramação, em especial de materiais polifônicos e com muitas imagens e gráficos, em que as informações precisam estar claras e bem colocadas na página para que a leitura tátil seja efetiva.

Os professores envolvidos com o projeto relatam também que o contato com alunos com deficiência visual em sala de aula de música, além de promover aprendizado constante, provoca a busca por novas práticas pedagógicas. Nesse contexto, o contato com a musicografia mostra ser uma abertura ao universo de interpretação desses alunos, tornando a relação professor-aluno mais eficaz e próxima.

\section{CONSIDERAÇÕES FINAIS: RESULTADOS E PERSPECTIVAS}

O Projeto teve recepção bastante positiva por parte da comunidade universitária. Ao fim do semestre, os bolsistas apontam principalmente a satisfação em aprender um novo código, que poderá ser bem aproveitado por eles como profissionais (como músicos e professores), e em participar da promoção da acessibilidade e acesso à música. Tornou-se também perceptível a necessidade de maior estudo sobre o uso de softwares (como os conhecidos Finale e MuseEscore) como ferramentas facilitadoras da produção de uma partitura em braille. Ainda sobre os softwares, há também espaço para a pesquisa no desenvolvimento de softwares cada vez melhores para produção de partituras braille, capazes de produzir textos mais complexos com esforço e tempo menor.

Para o longo prazo, os próprios bolsistas trouxeram sugestões para ampliação do ensino e estudo da musicografia braille, através de novas ações de ensino, pesquisa e extensão na área, com o objetivo de aperfeiçoar transcritores e métodos em um estudo sequencial do código musical em braille. $\mathrm{O}$ aluno com deficiência visual estudante de música precisa ser cada vez mais incluído na produção de partituras, como adaptador ou revisor, e mais alunos videntes estudantes de música precisam ser apresentados à musicografia braille em sua formação, de forma multidisciplinar. 


\section{REFERÊNCIAS}

TOMÉ, Dolores. Musicografia Braille: instrumento de inserção e formação profissional. Benjamin Constant, Rio de Janeiro, v. 1, n. 36, p. 1-13, março, 2007. Disponível em: http://revista.ibc.gov.br/index.php/BC/issue/view/78. Acesso em: 11 out. 2020.

UNIVERSIDADE DE BRASÍLIA. Institui a Política de Acessibilidade da Universidade de Brasília. Resolução do Conselho de Administração No 0050/2019. Brasília, 2019.

UNIVERSIDADE DE BRASÍLIA. Dispõe sobre os direitos acadêmicos de alunos regulares Portadores de Necessidades Especiais (PNEs) da UnB. Resolução do Conselho de Ensino, Pesquisa e Extensão N. 48/2003. Brasília, 2003. 